\title{
LOS IMPACTOS FISCALES DE UNA GUERRA DISTANTE: CRISIS Y RESTAURACIÓN DE LA REAL HACIENDA EN LA PROVINCIA DE YUCATÁN (1801-1821)*
}

\author{
ERNEST SÁNCHEZ SANTIRÓ \\ Instituto de Investigaciones Dr. José María Luis Mora ${ }^{\mathrm{a}}$
}

The fiscal impacts of a distant war: crises and restoration of the royal treasury in Yucatan province (1801-1821)

\begin{abstract}
Starting from the quantitative reconstruction of revenues and expenses of the Royal Treasury in the Yucatan province during the period 1801-1821, the paper shows the transition from an unbalanced regional fiscal structure that depended on colonial transfers (situados) to offset the deficit, to one self-sufficient structure in the context of the Independence War and the liberalism of the Cortes de Cadiz. An autonomy based on the indigenous capitation tax and the fiscal control of foreign trade that was made in the ports of the Yucatan Peninsula.
\end{abstract}

Keywords: Taxation, Independence War, Cortes de Cadiz, Yucatan, New Spain

JEL Codes: H20, N26, N46, N96

* Received 12 August 2012. Accepted 19 October 2012. Quiero agradecer los comentarios de Luis Jáuregui y Lorgio Cobá Noh, así como el apoyo al trabajo de archivo de Alexandra Rodríguez Medina y Julio César Rodríguez. Esta investigación ha recibido financiación del CONACYT (proyecto n. ${ }^{\circ}$ 153.670).

a Plaza Valentín Gómez Farías \#12, Col. San Juan Mixcoac, 03730 México D. F. Correo-e: esanchez@mora.edu.mx 


\section{RESUMEN}

A partir de la reconstrucción cuantitativa de los ingresos y egresos de la Real Hacienda en la provincia de Yucatán durante el periodo 1801-1821, el artículo muestra el tránsito de una estructura fiscal regional desequilibrada que dependía de las transferencias virreinales (situados) para compensar el déficit a una estructura autosuficiente en el marco de la guerra de Independencia y el liberalismo de las Cortes de Cádiz. Una autonomía adquirida gracias a la capitación indígena y al control fiscal del comercio externo que se realizaba en los puertos de la Península de Yucatán.

Palabras clave: Fiscalidad, Guerra de Independencia, Cortes de Cadiz, Yucatan, Nueva España

\section{INTRODUCCIÓN}

La historiografía sobre la Real Hacienda del imperio español a fines del periodo colonial ha adquirido un gran desarrollo, al igual que los estudios sobre la fiscalidad del virreinato de Nueva España durante el reinado de Carlos IV ${ }^{1}$. De igual manera, y para este mismo virreinato, contamos con una incipiente investigación sobre el real erario durante la guerra de Independencia. Estos trabajos han atendido, básicamente, a la desestructuración del aparato fiscal y al crecimiento de una fiscalidad extraordinaria ${ }^{2}$, así como a la evolución de algunos impuestos, especialmente las alcabalas y las contribuciones directas ${ }^{3}$; sin embargo, no contamos con un análisis sobre la fiscalidad regional en dicho periodo de crisis, cuando la casuística territorial constituye una seña de identidad del antiguo régimen colonial novohispano. Estas peculiaridades, atendidas de forma amplia, permitirían diferenciar el comportamiento desigual del erario regio durante el conflicto armado. Con este propósito se plantea un estudio sobre la Real Hacienda en la provincia de Yucatán ${ }^{4}$ durante el periodo 1801-1821.

Sobre este espacio, se dispone de una creciente y diversificada historiografía que ha reconstruido los tres aspectos más relevantes de su estructura

1 En el caso de los enfoques imperiales, destacan TePaske (1986), Klein (1995), Sánchez et al. (2001), Marichal (2006), y Grafe e Irigoin (2012). Para el caso novohispano, sobresalen Stein (1985), Pérez Herrero (1991), Jáuregui (1999) y Marichal (1999).

2 TePaske (1991) y Jáuregui (1999).

3 Serrano (2007) y Sánchez Santiró (2009).

4 Una muestra de que así era entendida por las autoridades virreinales, sin incluir por tanto todos los territorios que formaban la intendencia, se aprecia en el título que le dieron a la matrícula de tributarios del quinquenio 1816-1820: "Libro que contiene el resultado de la visita general de tributarios de la Provincia de Yucatán por estado y de los encomenderos... ». AGN, IV, caja 6.600, exp. 77. La cursiva es nuestra. 
hacendaria: el predominio de la capitación (el tributo de indios) y los impuestos mercantiles en la esfera de los ingresos, la existencia de un déficit estructural ante el creciente gasto militar regional a partir de la década de 1770 y, finalmente, la restauración del equilibrio fiscal gracias a las remesas (situados) que se enviaban a la provincia desde diversas tesorerías virreinales, caso de las cajas reales de Veracruz, México y Tabasco ${ }^{5}$.

De igual forma, contamos con una incipiente investigación que ha señalado los principales eventos vividos por la Real Hacienda en el espacio yucateco a raíz las abdicaciones de Bayona y la invasión napoleónica de 1808 y, posteriormente, del estallido del movimiento insurgente en septiembre de 1810. Eventos político-militares que afectaron en la distancia a la provincia de Yucatán, en la medida en que la región no sufrió una guerra de invasión, caso de España, ni fue escenario de una guerra civil, como sí lo fue la mayor parte del centro y norte del virreinato. Lo paradójico es que la Hacienda provincial acabó padeciendo una profunda crisis fiscal a partir de 1810 que derivaría en una situación cercana al colapso en 1814.

La historiografía ha mostrado las causas fundamentales de dicha crisis: el derrumbe de los ingresos con motivo de la abolición del tributo de indios y castas en 1810 (en el marco del proceso político gaditano y el estallido de la insurgencia) y la suspensión del envío de situados a la provincia a partir de 1811. También sabemos que los principales afectados por la caída en los ingresos fiscales fueron, por orden de importancia, los encomenderos, transformados en pensionistas de la Real Hacienda a partir de $1785^{6}$, que vieron suspendidos sus pagos y, en segundo lugar, los empleados de justicia y hacienda, y el ejército y las milicias provinciales, al sufrir descuentos y retrasos en sus haberes. ${ }^{7}$ Igualmente, se conocen los proyectos ideados entre 1811 y 1814 por las corporaciones regionales (destacan el comercio de Campeche, el cabildo de Mérida, la diócesis de Yucatán y la Diputación provincial) y por los ministros y oficiales de las tesorerías reales de la región para reducir el gasto y, sobre todo, elevar los ingresos fiscales; iniciativas que cristalizarían en la promulgación de un reglamento regional de libre comercio, publicado el 6 de abril de 1814, y en la restauración del tributo de indios en la provincia gracias al bando del 17 de noviembre de $1814^{8}$.

Sin embargo, y a pesar de algunos trabajos pioneros ${ }^{9}$, no disponemos de una reconstrucción pautada y global del impacto cuantitativo que tuvo la crisis fiscal en la Hacienda provincial yucateca, así como del resultado obtenido por las reformas emprendidas en 1814. De igual forma, la historiografía

\footnotetext{
5 Pérez-Mallaina (1978), Marichal (1999), Moreno Acevedo (2002), Campos García (2004), Quezada y Moreno (2005).

6 García Bernal (1972:50).

7 Moreno Acevedo (2002), Campos García (2004), Quezada y Moreno (2005).

8 Hernández Ortiz (2011).

9 Quezada y Acevedo (2005).
} 
presenta un fuerte desbalance en términos temporales, al enfocarse más en la crisis (c. 1810-1814) que en la reconstrucción de la Hacienda regional (1814$1820)$, con el agravante de que se desconoce el impacto fiscal del segundo periodo constitucional en la provincia (1820-1821).

Para atender a estos aspectos, el trabajo reconstruye cuantitativamente el desempeño de la Hacienda provincial yucateca en el periodo 1801-1821, como muestra de la situación previa y posterior a la crisis derivada de los fenómenos político-militares acaecidos en el bienio 1808-1810. Asimismo, se realiza una propuesta metodológica que permita agrupar los datos de forma significativa y modularlos temporalmente. El objetivo es mostrar cómo las soluciones fiscales ensayadas en el espacio regional durante el periodo 18101821 llevaron a una creciente divergencia de intereses con las instituciones de gobierno de la monarquía y el virreinato que, a su vez, determinarían la fiscalidad regional hasta mediados del siglo XIX.

\section{LA RECONSTRUCCIÓN DE LA CONTABILIDAD DE LA HACIENDA PROVINCIAL DE YUCATÁN (1801-1821): FUENTES Y METODOLOGÍA}

Dos cajas reales (tesorerías) articulaban territorialmente el real erario en Yucatán: la de Mérida y la de Campeche. Aunque existían otras unidades administrativo-fiscales, caso de la caja del Presidio del Carmen y la de Bacalar, en ambos casos se trataba fundamentalmente de pagadurías (término de la época), esto es, oficinas enfocadas a pagar el sueldo de las unidades militares presentes en esas localidades. Más aún, la caja del Carmen fungía como pagaduría de la caja de Veracruz, mientras que la caja de Bacalar estaba supeditada a las órdenes de la caja de Mérida ${ }^{10}$.

La reconstrucción de la contabilidad de la Hacienda provincial yucateca en el periodo tardocolonial (1801-1821) se enfrenta a dos problemas. En primer lugar, la carencia de fuentes: la historiografía ha trabajado, mayoritariamente, con las cartas-cuentas ${ }^{11}$ (resúmenes anuales del cargo y la data) publicadas por John J. TePaske y Herbert S. Klein ${ }^{12}$; el problema consiste en que, para el periodo 1801-1820, la obra de TePaske y Klein solo localizó seis cartas-cuentas para la caja de Campeche y otras seis para la de Mérida ${ }^{13}$, con el agravante de que casi todas pertenecen al periodo 1801-1808, lo cual no permite la reconstrucción del comportamiento fiscal regional para los momentos críticos posteriores al bienio 1808-1810.

10 Torales Pacheco (2008: 137-200) y Campos García (2004: 28-29).

11 Moreno Acevedo (2002), Quezada y Moreno (2005). En ciertos trabajos, la documentación ha sido complementada con informes de los oficiales de las cajas reales o con fuentes impresas del gobierno de Yucatán. Campos García (2004).

12 TePaske y Klein (1986-1988).

13 Concretamente: Campeche (1801, 1803, 1805, 1807, 1812, 1815); Mérida (1801, 1802, 1803, $1806,1808,1816)$. 
Para complementar la información de las cartas-cuentas publicadas hemos empleado libros manuales (diarios) y comunes de cargo y data de las cajas de Campeche y Mérida, así como informes y cortes de caja localizados en el Archivo General de la Nación. Además, se ha empleado documentación del Archivo General de Indias que presenta una doble naturaleza: informes sobre la situación de la Hacienda provincial durante el periodo 1809-1814 y las cartas-cuentas de la caja de Mérida para el periodo $1815-1819^{14}$. Gracias a ello, se ha contado con la documentación básica para reconstruir el desempeño de la Hacienda provincial.

El segundo problema es metodológico. La historiografía ha señalado que no se puede hacer un uso directo de las cartas-cuentas, ya que contienen un gran número de partidas que, en lugar de indicar un verdadero ingreso o egreso en las cajas reales, solo representan existencias y ajustes contables ${ }^{15}$.

Pero no solo se trata de depurar la fuente, sino también de determinar cómo organizarla y qué parte de ella hay que privilegiar. En este punto, la historiografía sobre la Hacienda provincial yucateca cuenta con la propuesta de Sergio Quezada y Elda Moreno Acevedo ${ }^{16}$, consistente en trabajar únicamente con los datos contenidos en la denominada masa común de la Real Hacienda, es decir, los ingresos pertenecientes a la Corona que se empleaban para el pago de la administración de justicia y hacienda, los gastos militares regionales y los pensionistas de las cajas yucatecas, en especial, los encomenderos. Esto dejó fuera del análisis los ramos particulares y remisibles ${ }^{17}$, es decir, ingresos fiscales de la monarquía que se empleaban en rubros específicos: en el primer caso, en el pago de diversos cargos eclesiásticos y en el sustento de fondos piadosos (ramo de bulas de Santa Cruzada), así como en la retribución de algunos ministros y oficiales de la Real Hacienda que no era cubierta por la masa común (ramo de penas de cámara); en el segundo caso, se trataba de ingresos propios de la Real Hacienda destinados a gastos de la Corona en sus dominios de Europa (nos referimos a diversos monopolios reales - azogue, naipes, tabaco - y donativos), lo que los convertía en verdaderas remisiones netas de fondos fiscales de Nueva España a la metrópoli. Asimismo, existían los ramos ajenos, es decir, los ingresos que entraban a las cajas reales a título de depósito y custodia, que pertenecían a individuos y corporaciones (los montepíos de empleados y militares al servicio de la Corona, o los fondos de la Iglesia y las repúblicas de indios), y que se tenían que emplear en sus gastos.

Consideramos que dejar fuera del análisis a los ramos particulares y remisibles, especialmente a partir de la crítica coyuntura de 1808, impide

\footnotetext{
14 Hernández Ortiz (2011). Agradezco al investigador Sergio Quezada el haberme facilitado la consulta de la carta-cuenta de 1819.

15 TePaske (1983), Brading (1985), Pérez Herrero (1991), Marichal (1999).

16 Quezada y Acevedo (2005).

17 Para esta división contable, véase: Fonseca y Urrutia (1845-1853).
} 
apreciar que las autoridades políticas regionales optaron por emplear estos recursos para pagar los gastos adscritos a la masa común, ante las penurias crecientes del erario. Una política que, llegado el momento, también aplicaron a los fondos ajenos. Así, en este trabajo, se ha optado por incluir el análisis de los cuatro rubros: ramos de la masa común, particulares, remisibles y ajenos.

Para reconstruir el comportamiento hacendario de las cajas provinciales de Yucatán, hay que establecer los egresos e ingresos efectivos de dichas tesorerías. Así, atendiendo al doble criterio de computar los ramos que pertenecían a la Real Hacienda y evitar una doble contabilidad, hemos sustraído a los egresos y los ingresos de las cajas de Mérida y Campeche los ramos ajenos, las transferencias entre las cajas de la provincia y los ajustes contables ${ }^{18}$.

El apartado de los ingresos fiscales supone un problema específico, especialmente cuando se pretende reconstruir la manera en que los ministros y oficiales reales asentaban y valoraban su situación ${ }^{19}$. Para ello, hemos clasificado la información en cinco categorías. La primera, denominada ingreso total, es la mera suma de los cuatro ramos que aparecían en la contabilidad de las cajas reales (ramos de la masa común, particulares, remisibles y ajenos). La segunda, el ingreso propio, se refiere a los ingresos proporcionados por los ramos pertenecientes al rey, lo que implica descontar los ramos ajenos. La tercera, el ingreso disponible, muestra los recursos pertenecientes al rey con los que se contaba efectivamente tras desagregar los ajustes contables y la doble contabilidad. La cuarta, el ingreso de la caja,

18 Ramos ajenos de data en la caja de Mérida: comunidades de indios, holpatán (medio real de ministros), $1 \%$ de lanchas cañoneras, $2 \%$ y $4 \%$ de revisiones, depósitos de justicia ordinaria y de Real Hacienda, expolios de la mitra, montepíos de ministros, militar y de oficinas, propios de Campeche y propios y arbitrios de Mérida y data de diezmo de encomienda. Las transferencias de la caja de Mérida a la de Campeche aparecía en el rubro «otras tesorerías», mientras que los ajustes contables se encuentran en los ramos alcance de cuentas, buenas cuentas y fondo común. "Libro manual de data de la caja de Mérida de 1810», AGN, IV, caja 6.302, exp. 1. En la caja de Campeche los ramos ajenos de data eran: depósitos, montepíos de ministros, militar, oficinas y de cirujanos, marina de La Habana, temporalidades y arbitrio del 1\%, mientras que los ajustes contables aparecían en los ramos denominados fondo común de Real Hacienda, alcances de cuentas, cuenta con Mérida, cuenta con La Laguna (Presidio del Carmen), cuenta con Bacalar, cuenta con La Habana, cuenta con Veracruz. "Libro común de data de la caja de Campeche de 1810». AGN, CM, vol. 992. En otros años también podían aparecer ajustes contables en el ramo "cuenta con Tabasco» y en el de buenas cuentas. En el caso de los ingresos hemos descontado aquellos rubros que consignan ajustes contables (alcances de cuentas, buenas cuentas, Real Hacienda en común y reintegro de suplementos), así como los ingresos ajenos. En este caso y para la caja de Mérida eran: 1\% de lanchas cañoneras, $2 \%$ y $4 \%$ de revisiones, bienes de difuntos, depósitos de Real Hacienda, depósitos de justicias ordinarias, holpatán (medio real de ministros), montepíos de cirujanos, ministros, militar y de oficinas, partes del Consejo de Indias, peajes del camino de Sisal, propios y arbitrios de Mérida, temporalidades, $4 \%$ de descuentos para la guerra. «Libro manual de cargo de la caja de Mérida de 1810", AGN, CM, vol. 583. Los ramos ajenos en la caja de Campeche eran: depósitos, montepíos militar, de ministros, oficinas y cirujanos, temporalidades, marina y arbitrio de $1 \%$. «Libro común de cargo de la caja de Campeche de 1809», AGN, CM, vol. 3.435.

19 Véanse los informes de los ministros de las cajas de Mérida y Campeche sobre el estado de la Hacienda provincial en 1809, 1812 y 1814. AGI, México, leg. 3.145. 
consigna los recursos de la Corona efectivamente disponibles (tributos, rentas y derechos) que se originaban en el espacio fiscal de las cajas de Mérida y Campeche. Por tanto, no contabiliza las transferencias desde otras tesorerías del virreinato: los situados. Finalmente, el ingreso de la masa común es la entrada obtenida por las cajas reales de la provincia de Yucatán a partir de los ramos establecidos regionalmente con el propósito de atender básicamente al gasto militar, la administración hacendaria y de justicia y las pensiones de los encomenderos. Por consiguiente, no se consignan aquí los ingresos pertenecientes a la Real Hacienda creados para atender los gastos «particulares» o para ser remitidos a la metrópoli.

Las notables diferencias cuantitativas entre estas cinco categorías se ponen de manifiesto si se observa el promedio anual de ingresos brutos de la Hacienda provincial yucateca en el periodo 1801-1820, organizados quinquenalmente (Gráfico 1):

\section{GRÁFICO 1}

PROMEDIO ANUAL DE INGRESOS BRUTOS DE LA HACIENDA PROVINCIAL DE YUCATÁN (1801-1820)

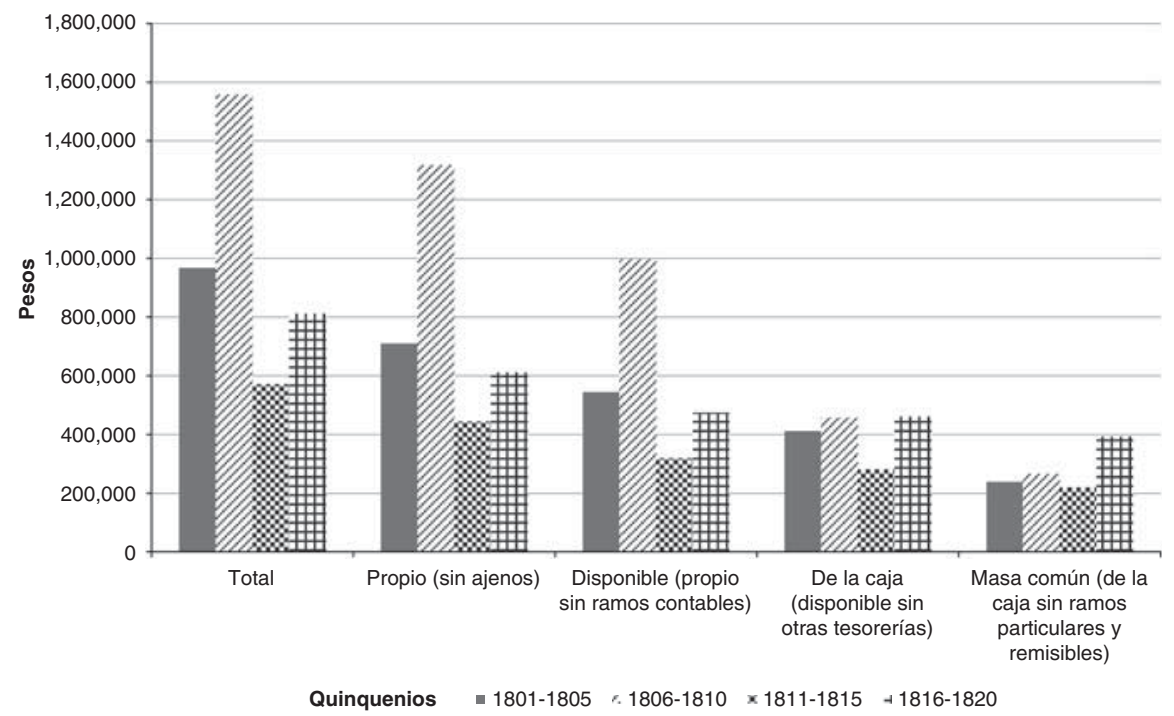

Fuente: Apéndice 1.A.

Así, por ejemplo, si atendemos al quinquenio 1801-1805, el promedio anual de los ingresos disponibles de la Hacienda provincial yucateca era un $44 \%$ menor que el de los ingresos totales que registraban los libros mayores de cargo (544.598 pesos frente a 967.817 pesos anuales) y un $75 \%$ inferior si 
solo se consideraban los ramos fiscales de la masa común (238.559 pesos). Igual comportamiento se reproduce en el resto de quinquenios aquí considerados.

\section{EGRESOS E INGRESOS DE LA HACIENDA PROVINCIAL YUCATECA (1801-1821): DE LA DEPENDENCIA A LA AUTONOMÍA FINANCIERA}

\subsection{Los egresos de la Hacienda provincial yucateca: guerra, administración y pensiones}

El gasto estructural (el monto y la composición) de la Real Hacienda en la provincia de Yucatán durante el periodo tardocolonial se estableció entre 1778 y $1785^{20}$. Los rubros fundamentales fueron tres: sueldos militares, pensiones pagadas a los encomenderos de la región y sueldos de la administración político-militar y hacendaria.

Con relación a los sueldos militares hay que distinguir entre el ejército y la milicia. Existían tres cuerpos de la fuerza armada regular en Yucatán: la compañía de dragones de Mérida, el batallón fijo de Castilla y la compañía veterana de artillería, estos dos últimos ubicados en el puerto de Campeche. La estructura y la distribución de las milicias partían de una lógica étnica: armar a los vecinos españoles, mestizos y pardos (mulatos) libres de la región, dejando al margen a la población indígena, que era mayoritaria. Dicha fuerza miliciana adquirió su fisonomía tardocolonial con el Reglamento para las milicias de $1778^{21}$.

Mientras que la totalidad del ejército contaba con un salario, no sucedía lo mismo con los milicianos. Algunas unidades de los batallones de milicias blancas estaban inactivas durante seis meses al año. Al estar en reserva, solo cobraban los grados que iban de cabo segundo a capitán, dejando sin estipendio a los soldados. En otros casos, como sucedía con las compañías sueltas de tiradores pardos libres, no recibían salario los cabos (primero y segundo) ni los soldados, es decir, el contingente más numeroso. Únicamente, se pagaba a toda la tropa cuando se estaba en estado de guerra y se precisaba una movilización general $^{22}$.

${ }^{20}$ Hemos determinado el gasto estructural a partir de dos criterios: la frecuencia y su funcionalidad. En la medida en que un rubro aparecía de forma reiterada y cubría una necesidad básica para el funcionamiento de la estructura política y hacendaria de la provincia, ha sido incluido en esta categoría. Sin embargo, gastos puntualmente elevados pero esporádicos, especialmente a partir de la década de 1790 (Quezada y Moreno 2005: 316), como los efectuados en gastos de fortificación o en armamento, han sido excluidos.

21 Reglamento (1778).

22 Reglamento (1778: 1, 19-20 y 32-34). El beneficio que recibían los contingentes armados adscritos a los batallones de voluntarios blancos, tiradores pardos libres y milicias urbanas que no recibían sueldo se hallaba en varias situaciones. En el caso de la población blanca y mestiza, el disfrute del fuero militar les eximía del control de la justicia civil, y en el caso de los pardos libres, 
A través de diversas fuentes ${ }^{23}$, hemos reconstruido la composición del ejército y las milicias, así como el coste que representaba para las cajas de Campeche y Mérida según las ordenanzas ${ }^{24}$. Gracias a ello, sabemos que el ejército regular en la península sumaba 645 efectivos, mientras que la fuerza miliciana ascendía a 2.846 hombres. El sueldo de los 3.491 individuos representaba un coste anual para las cajas reales de la provincia de 226.826 pesos, del que un $67,2 \%$ se destinaba al pago del ejército y el restante $32,8 \%$ al de las milicias. Una distribución que encuentra su lógica, como ya indicamos, en el hecho de que la mayoría de los soldados milicianos no cobraba un sueldo. A estos gastos en tropa reglada y milicias se añadió el sueldo de militares de alto rango asentados en la provincia de Yucatán que pertenecían a unidades cuya sede se ubicaba en otros territorios, por ejemplo, la capitanía general de Guatemala o la de Cuba. Su remuneración se cargaba a la caja de Mérida y aparecía en la contabilidad en el ramo «tropa reglada suelta», es decir, fuera de sus unidades. Durante la década de 1800 implicó, en promedio, un gasto anual de 4.563 pesos. La suma de estos tres conceptos permite cuantificar el coste estructural ${ }^{25}$ estipulado para los sueldos del «ramo de guerra» en la provincia de Yucatán durante el periodo tardocolonial.

Las pensiones destinadas a los encomenderos, que constituían la élite política y económica de la región, eran el segundo componente cuantitativo del gasto estructural de las cajas provinciales. Hasta la Real Cédula del 16 de diciembre de 1785, los indios de los pueblos y barrios de Mérida y Campeche encomendados a los descendientes de los antiguos conquistadores y primeros pobladores de la provincia pagaban directamente el monto del tributo a sus encomenderos ${ }^{26}$. Dicha norma incorporó las encomiendas yucatecas a la Corona, lo que transformó a los encomenderos en «pensionistas» de las cajas reales.

Si bien el monto de los tributos de encomienda dependía de la población que habitase los pueblos y barrios adscritos a cada encomendero/pensionista (por lo tanto oscilaba según la demografía, así como por la capacidad de las

\footnotetext{
(F'note continued)

además del goce del fuero, obtenían la exención del pago del tributo de castas, que constituía uno de los signos más visibles del estigma que arrastraba la población novohispana descendiente de esclavos africanos. Vinson (2005), Juárez (2005).

${ }^{23}$ La composición del ejército se ha obtenido del informe elaborado en 1814 por el contador y el tesorero de la caja de Mérida, mientras que para la milicia se hallan en el reglamento de 1778 . El pago del ejército adscrito a la caja de Mérida se ha obtenido de un informe de los ministros de la caja de Mérida de 1809. En la caja de Campeche, el gasto se ha reconstruido a partir de un informe que realizaron los oficiales de dicha caja en 1812. 1778 en Reglamento (1778); 1809 y 1812 (AGI, México, leg. 3.145), y 1814 en Torales Pacheco (2008: 176-180).

24 «Según las ordenanzas» señala dos situaciones. En primer lugar, que ese sería el pago si la totalidad de las plazas de los batallones y regimientos estuviesen ocupadas y, en segundo lugar, que los salarios se realizarían según los montos establecidos por las ordenanzas del ejército y las milicias.

${ }_{25}$ Cuando en un año específico hubiese vacantes, ya fuera por muerte del militar o miliciano, o por jubilación tras veinte años de servicio, el total de efectivos y su costo se modificaba.

${ }_{26}$ García Bernal (1972). Para la relación «directa» entre encomenderos e indios tributarios y la ruptura producida a partir de 1785, véase Cobá Noh (2009).
} 
autoridades para registrar esta evolución), se establecieron matrículas de tributarios para varios años, por lo general cinco. En la última matrícula previa a la guerra de Independencia, realizada entre noviembre de 1808 y febrero de 1810, los 14 partidos que componían la provincia de Yucatán consignaron 44.788 pesos anuales para el pago de tributos de encomienda, de los que un $83 \%$ se erogaba en la caja de Mérida y un $17 \%$ en la de Campeche ${ }^{27}$. En 1810, este monto se distribuía entre 56 encomenderos (individuos y corporaciones) ${ }^{28}$.

Los sueldos de la administración político-militar y hacendaria constituyeron el tercer rubro en importancia del gasto estructural de la Hacienda yucateca. Incluían los sueldos que percibían el gobernador, capitán general e intendente de la provincia, su asesor y auditor de guerra, los ministros (tesoreros y contadores) y oficiales de las cajas reales, y los empleados del resguardo terrestre (Mérida) y marítimo (Campeche) ${ }^{29}$ de las aduanas.

Hacia 1810, el gasto anual de la administración político-militar y hacendaria provincial ascendía a 26.474 pesos $^{30}$, siempre que todas las plazas estuviesen ocupadas y el cargo no fuese desempeñado por pensionistas (lo cual aminoraba el gasto en dicho rubro). Por otra parte, el distinto peso territorial en los gastos de la administración (59\% en la caja de Mérida y 41\% en la de Campeche) evidencia el papel de la ciudad de Mérida como capital política de la provincia. El único rubro en sueldos de la administración en el que la caja campechana superaba a la emeritense era en el resguardo de la aduana, pues el costo de una vigilancia marítima contra el contrabando era superior al de la terrestre.

En síntesis, el gasto estructural de las cajas de Mérida y Campeche en la primera década del siglo XIX ascendía a un monto cercano a los 302.000 pesos anuales (231.383 pesos en sueldos de tropa reglada, suelta y milicias, 44.788 pesos en pensiones de encomenderos y 26.474 pesos en los sueldos de la administración político-militar y hacendaria). A este egreso y, según las circunstancias, se añadían gastos extraordinarios de guerra (armamento, fortificaciones, vestimenta de militares, gastos de hospital y botica), de inválidos de guerra, que engrosaban la lista de pensionistas, de los condenados a los presididos y, llegado el momento, de los réditos de diversos préstamos colectados por la Real Hacienda en las cajas yucatecas ${ }^{31}$.

Ciñendo nuestra exposición al gasto hacendario provincial estructural entre 1801 y 1820, se observan cuatro etapas claramente diferenciadas (Cuadro 1):

27 La diferencia deriva del mayor número y densidad demográfica de los pueblos adscritos a la caja emeritense. AGN, IV, caja 2.388, exp. 1.

28 Cobá Noh, Indio (2009: 124).

29 En este caso, aparecen en la contabilidad algunas partidas de escaso monto dedicadas a tareas de mantenimiento de las naves (falúas) que vigilaban la bahía de Campeche, las cuales no han podido ser desagregadas plenamente de los sueldos que recibían los patrones y marineros de las embarcaciones.

30 Mérida, AGI, México, leg. 3.145; Campeche, AGN, CM, vol. 992.

31 El caso más notable fue la consolidación de vales reales (1804), que en Yucatán significó la entrada en las arcas reales de 260.868 pesos entre 1805 y 1808, lo que implicó una carga anual adicional de 13.043,4 pesos en concepto de réditos (5\% del capital). Wobeser (2003) y Cobá Noh (2009: 132-133). 
CUADRO 1

EVOLUCIÓN DEL GASTO ESTRUCTURAL DE LA HACIENDA PROVINCIAL DE YUCATÁN, 1801-1820 (PROMEDIOS ANUALES EN PESOS)

\begin{tabular}{|c|c|c|c|c|c|c|c|c|c|c|c|c|}
\hline Quinquenio & $\begin{array}{l}\text { Tropa } \\
\text { reglada }\end{array}$ & $\begin{array}{l}\text { C. } \\
(\%)\end{array}$ & $\begin{array}{l}\text { Tropa } \\
\text { suelta }\end{array}$ & $\begin{array}{l}\text { C. } \\
(\%)\end{array}$ & Milicias & $\begin{array}{l}\text { C. } \\
(\%)\end{array}$ & $\begin{array}{c}\text { Pensiones } \\
\text { encomenderos }\end{array}$ & $\begin{array}{l}\text { C. } \\
(\%)\end{array}$ & $\begin{array}{l}\text { Administración (político- } \\
\text { militar/ Hacienda) }\end{array}$ & $\begin{array}{l}\text { C. } \\
(\%)\end{array}$ & Total & $\begin{array}{l}\text { C. } \\
(\%)\end{array}$ \\
\hline 1801-1805 & 129.375 & - & 3.991 & - & 94.924 & - & 51.878 & - & 31.988 & & 312.156 & - \\
\hline $1806-1810$ & 164.564 & 27 & 5.136 & 29 & 151.348 & 59 & 44.788 & -14 & 28.422 & -11 & 394.257 & 26 \\
\hline $1811-1815$ & 114.704 & -30 & 2.467 & -52 & 92.878 & -39 & 9.921 & -78 & 25.429 & -11 & 245.400 & -38 \\
\hline $1816-1820$ & 155.094 & 35 & 9.345 & 279 & 105.406 & 13 & 43.249 & 336 & 25.613 & 1 & 338.706 & 38 \\
\hline
\end{tabular}

*C.: Crecimiento. Fuente. Apéndice 1.B. 
El primer quinquenio considerado (1801-1805) presenta un egreso próximo a lo previsto en las ordenanzas militares y a lo estipulado para los pensionistas/encomenderos ${ }^{32}$ y la administración político-militar y hacendaria: 312.156 pesos anuales frente a los 302.000 pesos calculados previamente como gasto estructural provincial. El segundo quinquenio (1806-1810), por el contrario, muestra una desviación notable al alza. No solo creció el gasto en una cuarta parte (26\%) sino que su composición interna evolucionó de forma desigual. Así, el pago en sueldos militares se disparó, especialmente el destinado a las milicias de blancos y pardos (se elevó un 59\%), y en menor medida por el pago a la tropa reglada y suelta (27\% y $29 \%$, respectivamente). Este comportamiento obedece a la movilización general de la milicia en la península de Yucatán en previsión de ataques de la armada británica después del desastre de Trafalgar y, a partir de 1808, de una posible invasión napoleónica. Una movilización que incrementó los gastos extraordinarios de guerra $^{33}$.

De forma inversa, el pago de pensiones a los encomenderos experimentó una leve reducción $(-14 \%)$ motivada por cuatro fenómenos: la caída en la renta que generaban las repúblicas de indios a partir del tributo (el pago de los encomenderos era un derivado de dicho ingreso), la progresiva reducción del número de encomenderos ${ }^{34}$, los auxilios extraordinarios que solicitó la Corona a los pensionistas con motivo de la guerra en Europa y, finalmente, la abolición del tributo de indios por parte de las Cortes de Cádiz en mayo de 1810. Una decisión que el virrey Venegas extendió a las castas ante el estallido de la insurgencia novohispana en septiembre de ese mismo año. Esta modificación transcendental (por los efectos que provocaría) se aplicó en las cajas yucatecas en noviembre de $1810^{35}$. El descenso moderado en el pago de la administración político-militar y hacendaria $(-11 \%)$ tuvo su

32 Las cantidades que aparecen en los quinquenios 1801-1805, 1806-1810 y 1816-1820 se corresponden, en los dos primeros casos, a informes sobre matrículas de tributarios realizadas en 1805 y 1810, mientras que los del último quinquenio surgen de la elaborada en 1816. En la medida en que el tributo de indios y castas fue abolido en Yucatán en noviembre de 1810 y no fue restaurado hasta noviembre de 1814, los datos del quinquenio 1811-1815 proceden de los pagos registrados en las cajas de Campeche y Mérida en el ramo de data denominado «tributos», que en su mayor parte fueron atrasos, con excepción del único pago verdaderamente cuantioso realizado en 1815. Para las matrículas de 1805, 1810 y 1816 consultar Terán (2010) y AGN, IV, vol. 6.600, exp. 77. Para los datos de 1815, véase: TePaske y Klein (1986-1988) y AGI, México, leg. 3.145.

33 En 1810 se señala que el intendente, gobernador y capitán general Benito Pérez Valdelomar había puesto sobre las armas «[a] los batallones de milicias, blanca y parda de esta capital [...] por disposición del Ilustrísimo Sr. Arzobispo virrey de Nueva España para defensa y precaución de la Provincia de una escuadra de la nación francesa destinada a invadir nuestras posesiones de esta América». Libro manual de data de la caja de Mérida de 1810, AGN, RH, vol. 6.302, exp. 1. La cursiva es nuestra.

${ }^{34}$ En 1810, el número de pensionistas era de 55, mientras que en 1816 ya solo sumaban 31 . Cobá (2009: 124) y AGN, IV, vol. 6.600, exp. 77.

35 Libro manual de data de la caja de Mérida de 1810, AGN, RH, vol. 6.302, exp. 1. Para la abolición del tributo en Yucatán: Campos García (2004), Quezada y Moreno (2005) y Cobá Noh (2009) 
origen en las vacantes de algunas plazas de la administración hacendaria, así como en descuentos aplicados por concepto de auxilios a la Corona.

Se produjo un cambio de tendencia en el siguiente quinquenio (18111815), momento en el que la Hacienda provincial vivió las derivaciones fiscales de eventos políticos y militares nacidos fuera de la región, a saber: el constitucionalismo gaditano y la insurgencia novohispana. Fue entonces cuando el gasto estructural cayó un 38\% respecto al nivel alcanzado en el lustro anterior y, más relevante todavía, fue inferior al gasto mínimo estructural (respecto a los 302.000 pesos anuales quedó un 19\% por debajo). En este caso, el descenso fue generalizado en todos los componentes del gasto, aunque con una distribución también muy desigual.

El primer punto que llama la atención es la reducción en el gasto militar. En la medida en que la insurgencia no tuvo arraigo en la provincia de Yucatán, las autoridades regionales redujeron el gasto en ejército y milicias cuando en el resto del virreinato no hacía más que crecer como resultado de la guerra civil que se libraba desde septiembre de $1810^{36}$. Un descenso en el egreso motivado, como veremos, por la caída en los ingresos.

Para aminorar los sueldos militares se emplearon dos mecanismos. Por una parte, la reducción en los haberes: si en 1811 se habían ajustado "por la escasez de caudales» que padecían las cajas reales ${ }^{37}$, la ausencia de recursos llegó a tal punto que derivó en una reducción generalizada. A partir de agosto de 1812, y previo acuerdo de la Junta provincial de Real Hacienda, se redujo un $50 \%$ el sueldo de toda la oficialidad de la provincia, dejando intacto el haber de los grados de tropa y suboficiales, desde tambores y soldados hasta cabos y sargentos. Unos pagos parciales que se realizarían «hasta que la Real Hacienda tenga con qué verificarlos» en su totalidad ${ }^{38}$. El otro mecanismo fue la disminución de los efectivos movilizados con cargo a las tesorerías de la región. En este sentido, una parte del batallón de Castilla y de las milicias blancas y pardas adscritas a la caja de Campeche fue trasladada a la intendencia de Veracruz para apoyar las operaciones del ejército realista ${ }^{39}$, de forma que su sueldo se transfirió a la tesorería veracruzana.

Igual situación vivieron los ministros y oficiales de las cajas reales de Mérida y Campeche, al experimentar una reducción en sus salarios del orden del $50 \%$. Algunos grupos implicados en las tareas de vigilancia de las aduanas, como los marineros del resguardo de Campeche, tuvieron una reducción inferior (33\%) en función de la peligrosidad de su actividad.

36 Archer (1981).

37 Libro común de data de la caja de Campeche de 1811. AGN, CM. Vol. 2.189, fols. 12-21.

38 Libro común de data de la caja de Mérida de 1812. AGN, CM, vol. 2.772, fols. 72v-89v.

39 AGN, In, vol. 134.

40 Esta reducción también afectó a las máximas autoridades de la provincia, empezando por el gobernador, intendente y capitán general, cargos en posesión del brigadier Manuel Artazo desde 1811. Libro común de data de la caja de Mérida de 1812. AGN, CM, vol. 2.772, fols. 72v-73. 
Si, finalmente, la caída registrada tanto en los sueldos del ramo militar como en los de administración no fue tan aguda como cabía esperar (11\%) fue debido a que, cuando en 1815 mejoraron los ingresos, se procedió a resarcir parte de los atrasos acumulados en el periodo 1811-1814 ${ }^{41}$.

Sin lugar a dudas, el grupo más castigado por la caída en los ingresos de las cajas yucatecas fue el de los pensionistas/encomenderos (se les redujo un $78 \%$ ), ya que la fuente de sus ingresos, el tributo de indios, se abolió en la provincia a partir de noviembre de 1810, por lo que dejaron de percibir su usufructo. Si bien en 1811 todavía cobraron algunos atrasos de años anteriores (especialmente en la caja de Mérida), los años críticos fueron los del trienio 1812-1814 en que no percibieron nada. Solo con la restauración del tributo en noviembre de 1814 lograron recuperar esta fuente de ingresos, que se hizo efectiva a partir de $1815^{42}$.

En el último quinquenio (1816-1820), inserto políticamente en el contexto de la restauración absolutista de Fernando VII, se produjo una clara recuperación de los egresos (un 38\%). En la medida en que, como veremos más tarde, las autoridades de la provincia consiguieron incrementar los ingresos regionales de la Real Hacienda, las tesorerías de Campeche y Mérida volvieron al nivel de gasto de principios del siglo XIX que, recordemos, era el que se correspondía con el egreso estructural previsto por la Corona en la provincia (unos 302.000 pesos anuales), e incluso a un nivel levemente superior.

Dos grupos salieron claramente favorecidos durante el sexenio absolutista. Por una parte, el ejército regular y las milicias de blancos y pardos libres (a quienes se incrementó un 35\%, un 279\% y un 13\%, respectivamente) $)^{43}$; y, por la otra, los encomenderos (cuyos ingresos aumentaron un $336 \%$ ). Los recursos obtenidos en concepto de tributos de encomiendas a partir de 1815 permitieron regresar al nivel de egresos existente en el quinquenio de 1806-1810.

¿Dónde está el origen de esta recuperación? Contestar esta pregunta es adentrarse en el problema de la evolución de los ingresos, así como en el significado de este proceso.

${ }^{41}$ En 1815 se abonaron en la caja de Mérida, por concepto de salarios de Real Hacienda y empleados del resguardo, 35.200 pesos, cuando en el quinquenio 1806-1810 este rubro apenas superó en promedio los 17.400 pesos anuales. AGI, México, leg. 3.145.

42 Para las protestas de este grupo, véase: Campos García (2004), Cobá Noh (2009) y Hernández Ortiz (2011)

${ }^{43}$ El número de militares (ejército y milicias) en servicio en las localidades de Mérida, Campeche y Bacalar en diciembre de 1820, en la antesala, pues, de la independencia, era de 2.348 efectivos, a los que había que añadir 5.520 distribuidos por los pueblos de la península, agrupados en compañías de milicias blancas, de tiradores pardos libres y en compañías milicianas urbanas (en ese año sumaban 12 compañías). De los militares en servicio en los núcleos principales (Mérida, Campeche y Bacalar) solo se empleaba diariamente a 712, es decir, el 30\%, lo cual representaba un notable ahorro para la Hacienda provincial. Una economía que fue posible en tanto en cuanto la península no fue un teatro de operaciones bélicas durante la década de 1810. «Estado general de la fuerza en actual servicio que existe en la capital de Mérida, Campeche y Bacalar, y de los empleados diariamente en el servicio, 28 de diciembre de 1820». AGMM, ramo de ultramar (México), caja 5.385. 


\subsection{Los ingresos de la Hacienda provincial yucateca: tributo, comercio y situado}

El volumen y la participación de los ingresos de los ramos de la masa común respecto a las obligaciones adscritas a ellos permite determinar la salud financiera de la Real Hacienda en el espacio provincial y virreinal. Al centrarnos en ellos, se aprecia que el ingreso fiscal regional se basaba en una combinación de impuestos sobre el comercio interno (alcabalas de tierra e impuestos sobre tiendas) y externo (alcabalas de mar y almojarifazgos), la producción local de aguardiente de caña (denominado «del país» por contraposición al aguardiente importado de Cuba) y la capitación (el tributo de indios) - véase el Cuadro 2 - La suma de estos tres rubros osciló durante las dos primeras décadas del siglo XIX entre el 77 y el 93\%, como niveles inferior y superior, del total de los ingresos fiscales de la masa común. El resto lo componía una miscelánea de estancos y contribuciones directas sobre el sueldo de los empleados públicos (estancos del papel sellado, juego de gallos, pólvora, naipes y tabaco ${ }^{44}$ y la media annata secular), así como otros ramos menores (multas, composición de tierras, derecho de sal, derecho de tiendas, bienes mostrencos, etc.).

Si bien este era el estado general de los ingresos provinciales, las diferencias entre las dos tesorerías yucatecas eran notables, como podemos apreciar en los siguientes datos (Gráficos 2 y 3):

\section{CUADRO 2}

COMPOSICIÓN Y EVOLUCIÓN DE LOS INGRESOS DE LA MASA COMÚN DE LA HACIENDA PROVINCIAL YUCATECA (1801-1820) (PROMEDIO ANUAL EN PESOS)

\begin{tabular}{|l|c|c|c|c|c|c|c|c|c|c|}
\hline Quinquenio & Tributo & $\%$ & $\begin{array}{c}\text { Alcabalas y } \\
\text { almojarifazgos }\end{array}$ & $\%$ & $\begin{array}{c}\text { Aguardiente } \\
\text { del país }\end{array}$ & $\%$ & Resto & $\%$ & Total & $\%$ \\
\hline $1801-1805$ & 109.599 & 46 & 61.768 & 26 & 12.092 & 5 & 55.099 & 23 & 238.559 & 100 \\
\hline $1806-1810$ & 110.994 & 42 & 84.723 & 32 & 14.530 & 5 & 55.072 & 21 & 265.319 & 100 \\
\hline $1811-1815$ & 32.474 & 14 & 118.767 & 52 & 19.348 & 9 & 48.590 & 22 & 219.180 & 100 \\
\hline $1816-1820$ & 135.693 & 35 & 191.239 & 49 & 36.284 & 9 & 29.037 & 7 & 392.253 & 100 \\
\hline
\end{tabular}

Fuente: Apéndice 1.A.

${ }^{44}$ Como muestra de la casuística propia del antiguo régimen, se constata que ramos, en principio remisibles, como eran los estancos de naipes y tabaco, formaban parte de los ramos de la masa común en las cajas de Yucatán. El escaso ingreso neto que generaban en la región y las necesidades locales provocaron este hecho. Como ejemplo, véase: Libro común de cargo de la caja de Campeche (1802). AGN, CM, caja 501. Cabe señalar que el estanco del tabaco en Yucatán, a diferencia del resto del virreinato, nunca representó un ingreso considerable para las cajas reales. De hecho, apenas cubría los gastos de la materia prima y el pago de los empleados del monopolio. Incluso, en muchos años, tuvo déficits que tuvieron que cubrirse con los excedentes del estanco de la pólvora. AGI, México, leg. 3.145. 


\section{GRÁFICO 2 \\ COMPOSICIÓN Y EVOLUCIÓN DE LOS INGRESOS DEL RAMO COMÚN DE LA \\ CAJA DE MÉRIDA (1801-1820)}

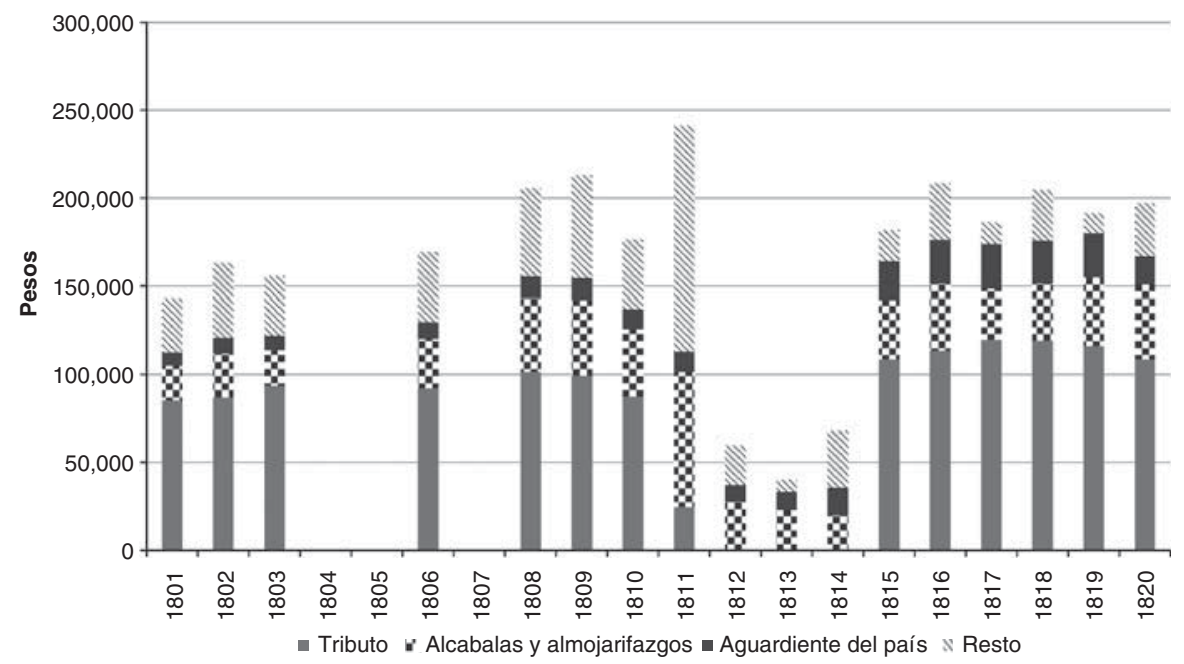

Fuente: Apéndice 1.A.

Claramente, la caja de Mérida fincaba sus ingresos en el tributo de indios, al representar, en promedio, el $48 \%$ de los ingresos anuales durante el periodo 1801-1820, mientras que el segundo rubro en importancia, los ingresos sobre el comercio interno y externo, aportaba un promedio del $21 \%$. Por tanto, era una tesorería que obtenía sus recursos a partir de la relación de vasallaje que existía entre la Corona y los indios de república de la península de Yucatán. Frente a esta situación, la tesorería de Campeche evidencia una caja encargada de fiscalizar el movimiento mercantil articulado a partir del puerto campechano, que aportaba, en promedio y durante el mismo periodo, el $72 \%$ de los ingresos, lo que deja a mucha distancia la capitación (13\%) o los ingresos derivados de la producción local de aguardiente de caña $(6 \%)^{45}$.

La evolución de los ingresos de la masa común de ambas tesorerías y su comparación con los gastos estructurales de la monarquía en la provincia permiten apreciar las contradicciones y tensiones a las que se vio sometida la Real Hacienda durante las dos primeras décadas del siglo XIX (Cuadro 3).

La primera constatación que surge de la comparación entre los gastos estructurales y los ingresos fiscales de la masa común durante el primer quinquenio (1801-1805) es la existencia de un déficit estructural elevado

45 El puerto de Campeche se había beneficiado de las medidas liberalizadoras aprobadas por la Corona a partir de la década de 1760. Pérez-Mallaina (1978). 


\section{GRÁFICO 3}

COMPOSICIÓN Y EVOLUCIÓN DE LOS INGRESOS DEL RAMO COMÚN DE LA

CAJA DE CAMPECHE (1801-1820)

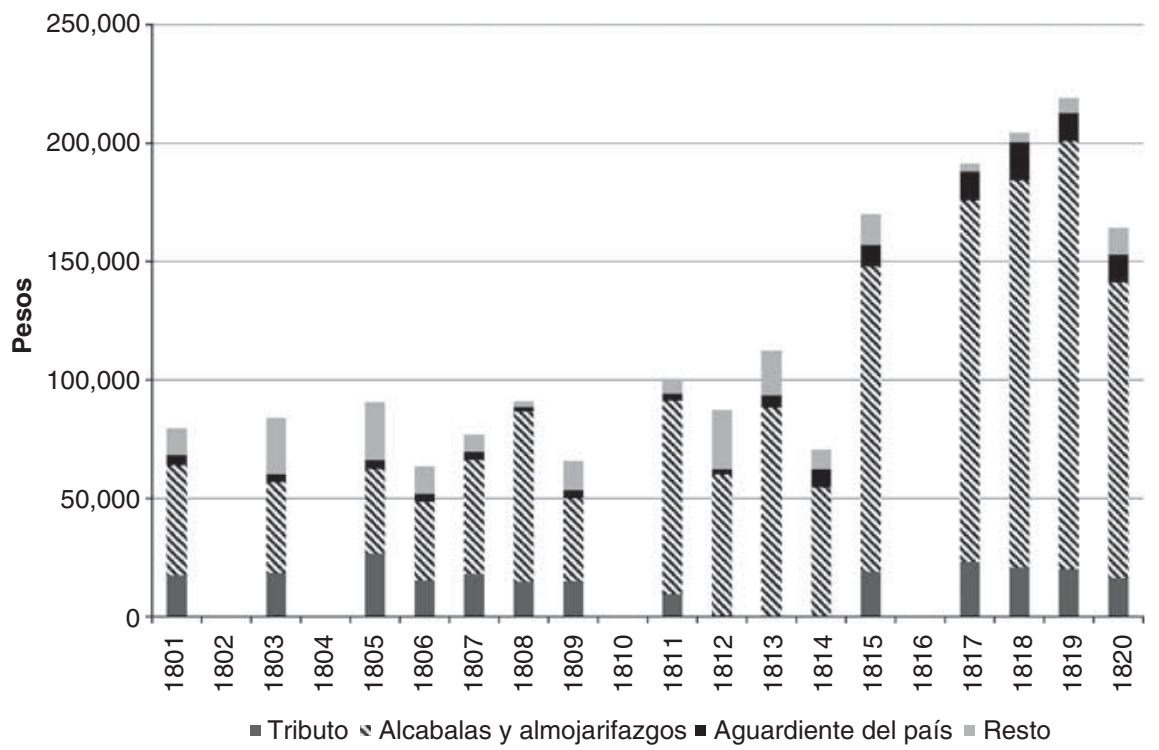

Fuente: Apéndice 1.A.

CUADRO 3

COMPARACIÓN ENTRE EL GASTO ESTRUCTURAL Y LOS INGRESOS DE LA MASA COMÚN DE LA HACIENDA PROVINCIAL DE YUCATÁN (1801-1820) (PROMEDIO ANUAL EN PESOS)

\begin{tabular}{|l|c|c|c|c|c|}
\hline Quinquenio & $\begin{array}{c}\text { Gasto } \\
\text { estructural }\end{array}$ & $\begin{array}{c}\text { Crecimiento } \\
(\boldsymbol{\%})\end{array}$ & $\begin{array}{c}\text { Ingreso masa } \\
\text { común }\end{array}$ & $\begin{array}{c}\text { Crecimiento } \\
(\boldsymbol{\%})\end{array}$ & Diferencia \\
\hline $1801-1805$ & 312.155 & - & 238.559 & - & -73.596 \\
\hline $1806-1810$ & 394.257 & 26 & 265.319 & 11 & -128.938 \\
\hline $1811-1815$ & 245.399 & -38 & 219.180 & -17 & -26.219 \\
\hline $1816-1820$ & 338.706 & 38 & 392.252 & 79 & 53.546 \\
\hline
\end{tabular}

Fuente: Apéndices 1.A. y 1.B.

(73.596 pesos, es decir, del 23,5\%). Una característica apuntada por el conjunto de la historiografía que ahora podemos cuantificar en su magnitud. La compensación del faltante se realizaba con las transferencias (situado) enviadas desde la caja de México, mayoritariamente vía Veracruz, que se 
efectuaban al menos desde la década de $1740^{46}$. Gracias a este mecanismo, de manera periódica aunque con lagunas, se remitieron situados a las cajas de Yucatán por valores que oscilaron entre los 100.000 y los 200.000 pesos anuales, según los recursos disponibles y las necesidades ${ }^{47}$. Con ellos no solo se cubría el descubierto que generaba el gasto estructural de la Hacienda provincial, sino que surgía un pequeño excedente que, o bien quedaba como existencia para el siguiente ejercicio o bien completaba el pago de otros gastos como las pensiones de inválidos, huérfanos y viudas, los sueldos de algunos empleados (en especial, los del estanco del tabaco), además de financiar parte del gasto en armamento y fortificaciones.

Si bien el gasto estructural creció con motivo de la amenaza militar británica y, a partir de 1808, de Francia, los ingresos de la masa común no se elevaron en el mismo grado (un $26 \%$ y un $11 \%$, respectivamente) durante el segundo quinquenio (1806-1810). El mayor esfuerzo recaudatorio se basó en la actualización de las matrículas de tributos (en la de 1805 se computaron 81.295 tributarios y en la de 1810 fueron 86.025 tributarios) y en los ingresos derivados de la fiscalización vía almojarifazgos y alcabalas de mar y de tierra del comercio neutral que se realizó por el puerto de Campeche y el denominado surgidero de Sisal (un pequeño puerto cercano a la ciudad de Mérida). Un control que se hizo más evidente a partir de 1806, al abrigo de la política desplegada por la monarquía para evitar el acoso o bloqueo de los puertos del Caribe por parte de la armada británica tras el desastre naval de Trafalgar ${ }^{48}$.

A pesar del incremento en la recaudación, el déficit anual promedio se elevó al 32,7\% (128.938 pesos) por la movilización general de las milicias provinciales y del ejército regular como medida preventiva ante una posible invasión. Este desequilibrio solo pudo compensarse con el envío de situados mucho más cuantiosos (Gráfico 4).

Si en el quinquenio 1801-1805, los situados enviados desde la caja de Veracruz a la de Campeche fueron, en promedio, de 108.118 pesos anuales, en el siguiente periodo (1806-1810) la cifra creció un 238\%, al alcanzar los 366.243 pesos anuales, con 1808 como cénit en el envío de recursos a las tesorerías yucatecas (703.716 pesos).

La abolición del tributo de indios por parte de las Cortes de Cádiz en mayo de 1810 y su aplicación en la provincia de Yucatán a partir de noviembre ${ }^{49}$ fue el principal responsable de que los ingresos fiscales de la masa común cayesen de forma notoria (un 17\%) respecto al quinquenio 1801-1805. Este hecho fue paralelo a la pérdida de otra fuente de ingresos fundamental para las arcas provinciales: las remesas. A pesar de la distancia,

\footnotetext{
46 AGI, México, leg. 2.027.

47 AGI, México, leg. 3.145 y México, leg. 1.145.

48 Terán (2010) y Pérez-Mallaina (1978). Para el funcionamiento del comercio neutral, véase Marichal (1999).

49 Quezada y Moreno (2005); Cobá Noh (2009) y Hernández Ortiz (2011).
} 


\section{GRÁFICO 4 \\ SITUADOS RECIBIDOS POR LA CAJA DE CAMPECHE DESDE LA CAJA DE VERACRUZ (1801-1820)}

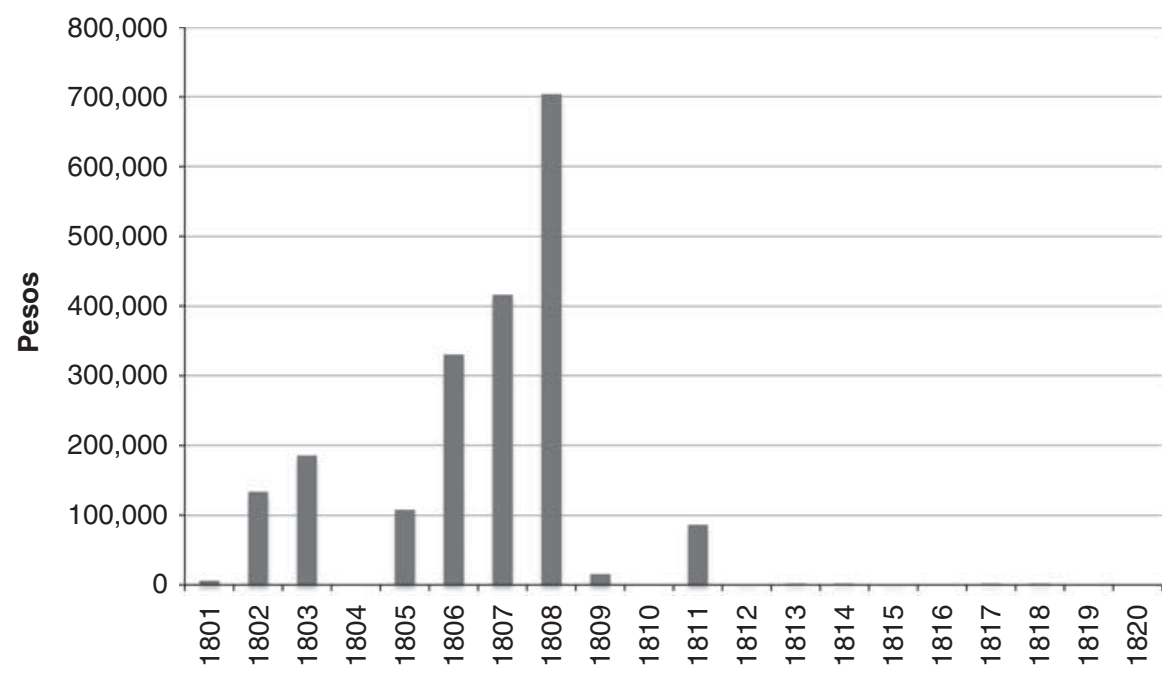

Fuente: Apéndice 1.C.

la guerra civil desatada en el centro y norte del virreinato en setiembre de 1810 tuvo una clara consecuencia para la provincia de Yucatán: se suspendió el envío del situado a partir de 1811, año en que todavía se recibieron 85.856 pesos. Desde 1812 y hasta 1820 su participación en el conjunto de los ingresos provinciales pasó de ser escasa (un promedio de 18.226 pesos anuales en el quinquenio 1811-1815) a insignificante (678 pesos en el quinquenio 1816-1820).

Si el déficit no fue mayor de lo que en principio se podría pensar (26.219 pesos anuales en promedio, inferior pues al acaecido entre 1801 y 1810) se debió a la combinación de la ya aludida reducción en los gastos y a la elevación de la tributación sobre el comercio interno y externo. Así, a partir del 24 septiembre de 1810, la alcabala pasó del 6 al 8\% (lo que significó una elevación del 33\% en la tasa) y se introdujeron dos nuevos impuestos: el pago de tres pesos por cada arroba de cera que se importase (en especial de Cuba) y dos pesos por cada carga de cacao de Tabasco, Guayaquil, Caracas y Magdalena que entrase en los puertos de la provincia. Estos gravámenes se habían aprobado como parte de las garantías otorgadas por el virrey Francisco Xavier Venegas para la recolección del «Préstamo patriótico» de 20 millones de pesos que había solicitado la Junta Central a Nueva España. En la medida en que el Consulado de Mercaderes de México había fungido 
como intermediario de la operación, la Real Hacienda había previsto ceder los productos de estos impuestos a las arcas de la corporación ${ }^{50}$. Sin embargo, ante la penuria que vivía la Hacienda provincial yucateca, el gobernador y la intendencia optaron por emplear estos fondos regionalmente, sin remitirlos a la tesorería del consulado ${ }^{51}$. Finalmente, los datos fiscales sugieren que la agroindustria azucarera en la provincia estaba experimentando un proceso de expansión, especialmente en la producción de aguardiente de caña ${ }^{52}$. Si en el quinquenio 1806-1810 se habían recaudado 14.530 pesos anuales en promedio (lo que significaba una producción anual de 29.060 barriles de aguardiente - se trataba de una contribución directa que desde 1790 gravaba con dos pesos cada barril fabricado-) en el quinquenio 1811-1815 se obtuvo un 33\% más, al registrarse fiscalmente una producción anual de 38.696 barriles (consultar Cuadro 2).

Al combinar estos factores, surge una evidencia: la crisis fiscal de la Hacienda provincial yucateca en el periodo 1811-1815 no provino de la elevación de los gastos militares, ni de una caída en la actividad económica regional provocada por la guerra de Independencia, como sí sucedió en gran parte del virreinato (así lo atestiguan los datos fiscales regionales sobre el comercio externo e interno y la agroindustria azucarera), sino de la desaparición del tributo de indios y del situado. Así, mientras la economía privada regional no se vio afectada por la insurgencia, la economía pública se desestructuró ante los impactos del reformismo gaditano y la ruptura de los mecanismos de transferencia de excedentes entre las cajas reales. La situación llegó a tal grado que la Real Hacienda provincial era insolvente ${ }^{53}$.

Si la Hacienda provincial no se declaró en bancarrota fue debido a que el erario empleó los fondos de los ramos particulares y remisibles, así como los ajenos (en "calidad de reintegro») para solventar un déficit que hasta entonces se había cubierto mayoritariamente con situados. Al carecer de esta herramienta a partir de 1811, el erario regional no solo suspendió el pago de las pensiones de los encomenderos y rebajó los sueldos del ejército y la administración, sino que incautó - a modo de préstamos forzosos - fondos ajenos como el ramo de depósitos de Real Hacienda y de justicias ordinarias, el ramo de bienes de difuntos o el del montepío de cirujanos. Sin embargo, la mayor apropiación se produjo en dos ramos ajenos que eran paralelos al cobro del tributo de indios, en cuanto que eran dos pagos anexos que realizaban los mismos causantes de la capitación indígena: los bienes o fondo de "comunidad de indios» y el medio real de ministros u holpatán (véase el Cuadro 4$)^{54}$.

\footnotetext{
50 Valle (1997: 400-409).

1 AGI, México, leg. 3.145.

2 Machuca (2011).

3 Quezada y Moreno (2005).

54 Torales (2008: 130-134) y Cobá Noh (2009).
} 


\section{CUADRO 4}

APROPIACIÓN DE LOS FONDOS DE COMUNIDADES DE INDIOS Y MEDIO REAL DE MINISTROS (HOLPATÁN) POR LA CORONA EN LA CAJA DE MÉRIDA, 1791-1820 (EN PESOS)

\begin{tabular}{|l|c|c|c|}
\hline Décadas & Comunidades de indios & Medio real de ministros & Total \\
\hline $1791-1800$ & 153.250 & 26.600 & 179.850 \\
\hline $1801-1810$ & 218.115 & 47.400 & 265.515 \\
\hline $1811-1820$ & 145.983 & 39.000 & 184.983 \\
\hline
\end{tabular}

Fuente: Documentos (1868).

El empleo de estos recursos por la Real Hacienda no era una novedad. Desde la década de 1790, la Corona se había apropiado de grandes sumas en ambos ramos ajenos en el marco de las diversas contribuciones extraordinarias que las repúblicas de indios novohispanas entregaron a la monarquía para apoyar su política exterior ${ }^{55}$. Así sucedió con los fondos ajenos yucatecos. Por el contrario, los montos obtenidos a partir de 1811 y hasta 1820 fueron apropiaciones enfocadas a cubrir parte del déficit de la Hacienda provincial yucateca, que pasó a engrosar la deuda pública.

Gracias a esta política de apropiación de los ramos particulares, remisibles y ajenos, la Hacienda provincial pudo cubrir el déficit, en especial durante los años de 1811 y $1813^{56}$. Sin embargo, en 1814 la situación se volvió crítica. Los ramos particulares, remisibles y ajenos estaban agotados, el crédito de la Hacienda pública provincial era inexistente y la presión de los militares, sometidos a descuentos, y de los encomenderos, que no cobraban desde 1811, se tornó insostenible ${ }^{57}$. En ese contexto, las autoridades provinciales, encabezadas por el gobernador e intendente Manuel de Artazo, adoptaron dos decisiones que cambiarían radicalmente el panorama de la Hacienda provincial, con repercusiones notables para la historia política y fiscal de Yucatán hasta la década de 1850.

El 6 de abril de 1814, al abrigo de las discusiones sobre "el libre comercio» derivadas de la constitución de Cádiz y con el apoyo decidido de la recién creada Diputación provincial, del cabildo de Campeche y de los ministros de las cajas provinciales, el entonces jefe político de la provincia, Manuel Artazo, publicó el Reglamento de derechos bajo el cual debe hacerse el comercio libre en esta provincia de Yucatán, con las potencias

55 Marichal (1999: 291). Especialmente notables fueron los montos entregados por las comunidades de indios de Mérida en 1795 (81.250 pesos), 1798 (60.000 pesos) y 1805 (95.000 pesos).

Documentos (1868) y Campos García (2004: 49 y 66).

56 AGI, México, leg. 3.145.

57 Cobá Noh (2009) y Hernández Ortiz (2011). 
amigas y neutrales ${ }^{58}$. Una norma que abría los puertos de la península de Yucatán (Campeche y Sisal) a las principales potencias mercantiles de la región: a los británicos, a través de su base comercial en Jamaica, y a los Estados Unidos, lo que configuraba un comercio directo con ambos actores sin la necesidad de navegar en barcos españoles ni la obligación de hacerlo desde o hacia puertos del imperio español.

El tratamiento historiográfico sobre esta medida ha oscilado entre la breve referencia a las oportunidades que representaba y la consideración de que produjo «beneficios... momentáneos» con poco impacto en la mejora de las finanzas públicas regionales ${ }^{59}$. Sin embargo, gracias a la reconstrucción de los ingresos fiscales de la caja de Campeche en el periodo 1801-1820 podemos afirmar que la medida representó un éxito notable para las arcas regionales. Así, como se aprecia en el Gráfico 3, el reglamento de libre comercio significó un salto notable en los ingresos mercantiles de la caja campechana. Si de ellos tomamos únicamente los referidos al comercio exterior (que debió tener un claro impacto en la actividad mercantil interna), se constata que entre 1801 y 1813 el promedio anual de ingresos fue de 53.891 pesos, mientras que en el periodo 1814-1820 la cifra se elevó a 130.488 pesos anuales. Un crecimiento del orden de 142\% que se basó, en gran medida, en las importaciones de textiles extranjeros (principalmente, británicos), que fueron la materia fundamental al representar el $45 \%$ de las importaciones a partir de $1814^{60}$.

Sin embargo, los aproximadamente 76.500 pesos adicionales que aportaba anualmente la apertura del libre comercio no cubrían la totalidad del déficit. En ese contexto, y en el marco de la restauración absolutista de Fernando VII, el gobernador e intendente de la provincia, Manuel Artazo, restableció el tributo de indios. Una medida que fue publicada por bando del 17 de noviembre de 1814 y que se adoptó con carácter interino hasta la resolución final de la Corona ${ }^{61}$. La aprobación del monarca vendría en 1815 , en el marco del proyecto de restauración del tributo de indios y castas en los territorios americanos de la monarquía, según Real Cédula del 1 de marzo de $1815^{62}$. Un restablecimiento que permitió levantar una matricula de tributarios en 1816 con validez hasta 1820, que arrojó un total de 94.124 tributarios (superior, por tanto, a las matrículas de 1805 y 1810) que aportarían

58 Pérez-Mallaina (1978) y Hernández Ortiz (2011).

59 Quezada y Moreno (2005) y Hernández Ortiz (2011: 31-32).

${ }^{60}$ El reglamento de libre comercio fue una de las opciones tratadas en el seno de la élite regional; de hecho, fue la triunfante frente a ciertas posturas que defendían la instauración de una contribución directa sobre los ingresos de la población (opción promovida por los ministros de las cajas provinciales) o la inversa, que proponía reducir a su mínima expresión las fuerzas militares (caso de la Diputación provincial). Hernández Ortiz (2011: 10-17).

${ }^{61}$ AGI, México, leg. 3.145. Hernández Ortiz (2011: 57-58).

62 Terán (2010: 284). A partir de entonces el tributo de indios y castas pasó a denominarse «contribución real». 
anualmente 140.739 pesos brutos, de los cuales el 69\% irían a parar a la Corona y el restante $31 \%$ a los encomenderos ${ }^{63}$.

La medida constituyó un claro éxito para la Hacienda provincial, puesto que la recaudación anual del quinquenio 1816-1820 fue, en promedio, de 135.693 pesos, es decir, la más alta alcanzada desde principios del siglo XIX.

No solo eso, la recaudación en concepto de tributos en la caja de Mérida, además de elevada, fue constante, lo cual dotó de certidumbre al erario público (véase el Gráfico 2).

La combinación de ambas medidas (el reglamento de libre comercio y la restauración del tributo) junto a una mayor actividad de la agroindustria azucarera regional condujo a una situación inédita para la Hacienda provincial yucateca: por primera vez, y de forma consistente, los ingresos de la masa común eran superiores a los gastos estructurales del erario provincial: el superávit anual de 53.546 pesos durante el quinquenio 1816-1820 así lo indica (véase el Cuadro 3). Asimismo, la salud financiera transmitía un cambio relativo en la composición del ingreso: si en los quinquenios 1801-1805 y 1806-1810, los tributos aportaron el $46 \%$ y el $42 \%$, respectivamente, de los ingresos totales de la masa común, frente al $26 \%$ y el $32 \%$ de los impuestos sobre el comercio interno y externo (alcabalas y almojarifazgos), en el quinquenio de 1816-1820 la situación se había invertido, ya que estos últimos pasaron a ocupar el primer lugar en la tributación (49\%), claramente por encima de la capitación indígena (35\%).

La otra cara de la moneda fue el elevado nivel de endeudamiento que arrastraba la Real Hacienda en la provincia. Si no tenemos en cuenta los 260.868 pesos entregados a la Corona como producto de la Consolidación de vales reales de 1804, y comparamos la deuda de 1809 (anterior, pues, al proceso político gaditano y a la insurgencia novohispana) con la existente en 1820, podemos apreciar el grado de apropiación que realizó la Corona sobre los ramos ajenos de la Real Hacienda: en 1809, la deuda de la caja de Mérida ascendía a 229.000 pesos, mientras que en 1820 ya sumaba 552.725 pesos, lo que significaba una elevación del adeudo de un $128 \%^{64}$; o, en otros términos, la deuda era un 33\% superior al promedio anual de ingresos de la provincia durante el quinquenio 1816-1820. Ambas realidades manifiestan el hecho de que se pudo recuperar la estabilidad de la caja en términos de tributación/ gastos estructurales, pero no se pudo restablecer el crédito público.

\subsection{Epílogo: la coyuntura del bienio 1820-1821}

La restauración de las Cortes y la jura de la Constitución de Cádiz por parte de Fernando VII en 1820 representaron una clara amenaza para la vida financiera de la Hacienda provincial yucateca. Si los decretos de las Cortes del periodo 1810-1814 volvían a tener vigencia, la persistencia del tributo de

${ }^{63}$ Cobá Noh (2009: 48-49). AGN, IV, vol. 6.600, exp. 77.

64 AGI, México, leg. 3.145, AGN, AHH, vol. 660, exp. 4 y Documentos (1868). 
indios (denominado contribución real desde 1815) quedaba en entredicho. De igual forma, el otro pilar de la fiscalidad regional, el reglamento de libre comercio de 1814, se vio amenazado cuando las Cortes españolas emitieron el decreto del 9 de octubre de 1820 que, entre otros aspectos, prohibía el comercio de algodones extranjeros. Una medida que hacía peligrar los ingresos elevados que había obtenido la Real Hacienda en la provincia con dicho tráfico durante el periodo 1815-1820.

La respuesta de las autoridades regionales (el jefe político de la provincia, el intendente, los ministros de la Hacienda nacional) y de las restauradas corporaciones gaditanas (ayuntamientos constitucionales y Diputación provincial) consistió en obstaculizar la aplicación de ambas medidas, al plantear cuestiones formales como los incumplimientos en la tramitación del decreto de Cortes, o al aplicar el criterio de «necesidad» que hacía inviable en lo inmediato el acatamiento de ambas medidas legislativas ante la amenaza que suponían para la Hacienda púbica regional. Una desobediencia que solo se salvaba con la aplicación en paralelo por parte de las autoridades provinciales de las reales órdenes del 15 y el 25 de marzo de 1820 que mandaban que no se hiciese novedad en el sistema de rentas hasta que de manera expresa lo ordenasen las Cortes ${ }^{65}$.

Si ambas medidas de las Cortes distanciaban a las autoridades y a la élite provincial yucateca del gobierno metropolitano de la Monarquía española, la voluntad de aplicar reformas que mejorasen las condiciones económicas de la provincia les llevó a entrar en conflicto con el jefe político de la provincia de México y virrey de Nueva España, Juan Ruiz de Apodaca. En la segunda sesión de la recién restaurada Diputación provincial, celebrada el 31 de mayo de 1820, la corporación aprobó el desestanco del tabaco, tomando en este caso como sustento el acuerdo unánime que adoptaron las Cortes españolas el 13 de marzo de 1814, poco antes de la restauración absolutista de Fernando VII, que aprobaba la abolición del estanco del tabaco ${ }^{66}$. En este caso, era la autoridad virreinal la que esgrimía las órdenes reales de no innovar en el sistema de rentas para condenar la actitud de la Diputación provincia de Yucatán ${ }^{67}$. El problema no consistía tanto en que la decisión adoptada en Yucatán minase una rica fuente de ingresos fiscales en la región, cosa que no sucedía, sino en el efecto de "contagio» que podía tener en otras regiones donde dicha renta era imprescindible para el pago del ejército. Un temor que se hizo realidad cuando diversas poblaciones de la intendencia de Veracruz desconocieron la continuidad del estanco del tabaco siguiendo el ejemplo yucateco ${ }^{68}$.

65 Hernández Ortiz (2011: 64-68) y Diputación (2006: 436, 508, 533-534, 594, 702).

66 Rieu-Millán (1990: 187).

67 «Expediente en que la Diputación provincial de Yucatán excediéndose en sus facultades ha extinguido la Renta del Tabaco y de cuyo procedimiento se queja el virrey de Nueva España». AGI, México, leg. 2.303. Diputación (2006: 333, 335, 447, 461 y 499).

68 AGI, México, leg. 2.303. 
Estos hechos no solo ponían en peligro los ingresos de la Hacienda nacional en Nueva España, sino que socavaban la autoridad del virrey en las regiones.

\section{CONCLUSIONES}

Las crisis política y bélica vividas por la monarquía española entre 1808 y 1810 significaron un grave quebranto para la Hacienda provincial yucateca en la medida en que los dos principales ingresos fiscales, el tributo de indios y el situado, dejaron de llegar a las tesorerías de la provincia a partir de 1811. Los intentos subsecuentes de equilibrar los gastos estructurales de la Hacienda provincial (reducciones en los salarios, suspensión en las pensiones, etc.) con los muy disminuidos ingresos fueron insuficientes, a pesar de que se había acentuado la apropiación de los ingresos de los ramos fiscales particulares y remisibles y que se vaciaron "con calidad de reintegro» los ramos ajenos de la Real Hacienda.

A mediados de 1814, el peligro de bancarrota de la Hacienda provincial era inminente, lo que derivó en la adopción de dos medidas extraordinarias: el reglamento de libre comercio y la restauración del tributo de indios.

Gracias a la reconstrucción cuantitativa del egreso y del ingreso de la Hacienda provincial durante el periodo 1801-1820, se ha podido constatar cómo ambas medidas supusieron un notable éxito que derivó en una situación radicalmente nueva: la autonomía fiscal de la región. Con los recursos fiscales generados en la provincia se pudo mantener el pago de las fuerzas armadas destinadas a asegurar el orden interno y la defensa externa, el salario de las administraciones de Hacienda y justicia, así como el pago de las pensiones de la élite regional (los encomenderos). La dependencia hacendaria respecto a las remesas enviadas por autoridades virreinales (los situados) fue sustituida por la autosuficiencia financiera.

Esta autonomía se vio seriamente amenazada con la restauración del régimen liberal en 1820, al ponerse en cuestión la continuidad del tributo de indios y al prohibirse el libre comercio de textiles extranjeros. Frente a estas amenazas, la actitud de las autoridades y de la élite regional fue la defensa de la recién adquirida autonomía fiscal, la cual pasaba por el control fiscal de los puertos de la península de Yucatán y por el mantenimiento de la capitación indígena. Unos principios que serían la seña de identidad de la élite regional cuando negociase su incorporación al naciente Imperio mexicano en 1821 y que atravesarían la pugna político-fiscal de la región hasta mediados del siglo XIX.

\section{BIBLIOGRAFÍA}

Archer, C. I. (1981): «Bourbon Finances and Military Policy in New Spain, 1759-1812». The Americas 37 (3), pp. 315-350. 
Brading, D. (1985): «Facts and Figments in Bourbon Mexico», Bulletin of Latin American Research IV (1), pp. 61-64.

Campos García, M. (2004): De provincia a estado de la república mexicana. La península de Yucatán, 1786-1835. Mérida: Universidad Autónoma de Yucatán/Consejo Nacional de Ciencia y Tecnología.

CoBÁ NoH, L. (2009): El «indio ciudadano» La tributación y la contribución personal directa en Yucatán, 1786-1825. Mérida: Universidad Autónoma de Yucatán/Instituto Mora.

Documentos relativos a los créditos de Yucatán a cargo del Gobierno Federal: al peligro que corrió el Estado en 1848 de ver consumada su total ruina por la guerra de los indios barbaros: a la generosidad con que en tan duro conflicto le auxiliaron las autoridades superiores de la isla de Cuba: a las demostraciones fraternales del Supremo Gobierno para salvarle de tan deplorable situación: y a la conducta de los ingleses en aquella guerra desoladora (1868). Mérida: Imprenta de J. D. Espinosa e hijos.

Fonseca, F. DE y Urrutia, C. DE (1845-1853): Historia de Real Hacienda, 6 vols. México D. F.: Imprenta de Vicente G. Torres.

García Bernal, M. C. (1972): La sociedad de Yucatán, 1700-1750. Sevilla: Escuela de Estudios Hispanoamericanos-CSIC.

Grafe, R. y IrigoIn, A. (2012): «A Stakeholder Empire: The Political Economy of Spanish Imperial Rule in America». The Economic History Review 65 (2), pp. 609-651.

Hernández Ortiz, S. (2011): «La política fiscal en el tránsito de la Hacienda Real a la Hacienda Pública. Imposiciones directas e ingresos comerciales en la provincia de Yucatán, 1813-1825». Tesis de licenciatura en Historia. Mérida: Universidad Autónoma de Yucatán.

JÁuREguI, L. (1999): La Real Hacienda de Nueva España: su administración en la época de los intendentes, 1786-1821. México D. F.: UNAM.

Juárez Martínez, A. (2005): «Las milicias de lanceros pardos en la región sotaventina durante los últimos años de la colonia», en J. Ortiz Escamilla (coord.), Fuerzas militares en Iberoamérica, siglos XVIII y XIX. México D. F.: El Colegio de México/El Colegio de Michoacán/Universidad Veracruzana, pp. 75-91.

KLEIN, H. S. (1995): Las finanzas americanas del imperio español, 1680-1809. México D. F.: Instituto Mora/Universidad Autónoma Metropolitana.

La Diputación provincial de Yucatán. Actas de sesiones, 1813-1814, 1820-1821 (2006). México D. F.: Instituto Mora.

Machuca, L. (2011): Los hacendados de Yucatán (1785-1847). México D. F.: CIESAS/Instituto de Cultura de Yucatán.

MARICHAL, C. (1999): La bancarrota del virreinato. Nueva España y las finanzas del Imperio español, 1780-1810. México D. F.: FCE/El Colegio de México.

Marichal, C. (2006): «Money, Taxes and Finance», en V. Bulmer-Thomas, J. H. Coatsworth y R. Cortés Conde (eds.), The Cambridge Economic History of Latin America, vol. I. Cambridge: Cambridge University Press, pp. 423-460. 
Moreno Acevedo, E. DE J. (2002): «La Real Hacienda en la provincia de Yucatán, 1721-1816». Tesis de licenciatura en Historia. Mérida: Universidad Autónoma de Yucatán.

Pérez Herrero, P. (1991): «Los beneficiarios del reformismo borbónico: metrópoli versus élites novohispanas». Historia Mexicana XLI (2), pp. 207-264.

Pérez-Mallaina Bueno, P. E. (1978): Comercio y autonomía en la Intendencia de Yucatán. Sevilla: Escuela de Estudios Hispano-Americanos-CSIC.

Quezada, S. y Moreno Acevedo, E. (2005): «Del déficit a la insolvencia. Finanzas y Real Hacienda en Yucatán, 1760-1816». Mexican Studies/ Estudios Mexicanos 21 (2), pp. 307-331.

Rieu-Millán, M. L. (1990): Los diputados americanos en las Cortes de Cádiz: igualdad o dependencia. Madrid: CSIC.

Sánchez SANTiRó, E. (2009): Las alcabalas novohispanas. Los dilemas en la construcción de la Hacienda nacional (1821-1857). México D. F.: Instituto Mora.

SÁnchez Santiró, E.; Jáuregui, L. e Ibarra, A. (coords.) (2001): Finanzas y política en el mundo iberoamericano. Del antiguo régimen a las naciones independientes. México D. F.: Universidad Autónoma del Estado de Morelos / Instituto Mora / UNAM-FE.

Serrano, J. A. (2007): Igualdad, uniformidad y proporcionalidad. Contribuciones directas y reformas fiscales en México, 1810-1846. México D. F.: Instituto Mora/El Colegio de Michoacán.

SteIN, S. J. (1985): «Prelude to upheaval in Spain and New Spain, 1800-1808: trust funds, spanish finance and colonial silver», en R. Garnerd y W. Taylor (eds.), Iberian colonies, New World societies: essays in memory of Charles Gibson. Pensilvania: State College, pp. 185-202.

Tepaske, J. J. (1986): "General Tendencies and Secular Trends in the Economies of Mexico and Peru, 1750-1810: The View from the Cajas of Mexico and Lima», en N. Jacobsen y H. J. Puhle (eds.), The Economies of Mexico and Peru during the Late Colonial Period, 1760-1810. Berlín: Colloquium, pp. 316-339.

Tepaske, J. J. (1991): «La crisis financiera del virreinato de Nueva España a fines de la colonia». Secuencia 19, pp. 123-140.

Tepaske, J. J. y Klein, H. S. (1986-1988): Ingresos y egresos de la Real Hacienda de Nueva España, 2 vols. México D. F.: Instituto Nacional de Antropología e Historia.

TERÁn, M. (2010): «Los tributarios de la Nueva España frente a la abolición y la restauración de los tributos, 1810-1822», en M. León-Portilla y A. Mayer (coords.), Los indígenas en la independencia y en la revolución mexicana. México D. F.: UNAM/INAH/Fideicomiso Teixidor, pp. 249-288.

Torales Pacheco, C. (2008): Expresiones de la Ilustración en Yucatán: textos de Agustín Pablo de Castro, S. J., Policarpio A. Echanove y José María de Lanz. México D. F.: Fundación E. Arocena. 
Valle Pavón, G. (1997): «El consulado de comerciantes de la Ciudad de México y las finanzas novohispanas, 1592-1827». Tesis doctoral. México D. F.: El Colegio de México.

VINSON III, B. (2005): «Los milicianos pardos y la relación estatal durante el siglo XVIII en México», en J. Ortiz Escamilla (coord.), Fuerzas militares en Iberoamérica, siglos XVIII y XIX. México D. F.: El Colegio de México/El Colegio de Michoacán/Universidad Veracruzana, pp. 47-60.

Wobeser, G. von (2003): Dominación colonial. La consolidación de vales reales, 1804-1812. México D. F.: Instituto de Investigaciones Históricas-UNAM.

\section{APÉNDICE 1.A}

FUENTES PARA LA RECONSTRUCCIÓN DEL INGRESO DE LA HACIENDA PROVINCIAL DE YUCATÁN (CAJAS DE MÉRIDA Y CAMPECHE) EN EL PERIODO $1801-1820$

\begin{tabular}{|c|c|c|}
\hline & Caja de Mérida & Caja de Campeche \\
\hline Año & Referencia & Referencia \\
\hline 1801 & TePaske y Klein (1986-1988) & TePaske y Klein (1986-1988) \\
\hline 1802 & TePaske y Klein (1986-1988) & n. d. \\
\hline 1803 & TePaske y Klein (1986-1988) & TePaske y Klein (1986-1988) \\
\hline 1804 & n. d. & n. d. \\
\hline 1805 & n. d. & TePaske y Klein (1986-1988) \\
\hline 1806 & TePaske y Klein (1986-1988) & AGN, CM, vol. 2.871 \\
\hline 1807 & n. d. & TePaske y Klein (1986-1988) \\
\hline 1808 & TePaske y Klein (1986-1988) & AGN, CM, vol. 1.546 \\
\hline 1809 & AGI, México, leg. 3.145 & AGN, CM, vol. 3.435 \\
\hline 1810 & AGN, CM, cajas 583 & n. d. \\
\hline 1811 & AGN, CM, cajas 574 & AGN, CM, vol. 1.891 \\
\hline 1812 & AGN, CM, vol. 2.989 & TePaske y Klein (1986-1988) \\
\hline 1813 & AGI, México, leg. 3.145 & AGN, CM, vol. 2.258 \\
\hline 1814 & AGI, México, leg. 3.145 & AGN, CM, vol. 1.460 \\
\hline 1815 & AGI, México, leg. 3.145 & TePaske y Klein (1986-1988) \\
\hline 1816 & TePaske y Klein (1986-1988) & n. d. \\
\hline 1817 & AGN, AHH, vol. 660, exp. 4 & AGN, AHH, vol. 660 , exp. 3 \\
\hline 1818 & AGN, CM, vol. 3.399 & AGN, AHH, vol. 941, exp. 1 \\
\hline 1819 & AGI, México, leg. 3.147 & AGN, AHH, vol. 570, exp. 8 \\
\hline 1820 & AGN, CM, vol. 2.068 & AGN, IV, caja 5.399, exp. 2 \\
\hline
\end{tabular}




\section{APÉNDICE 1.B}

FUENTES PARA LA RECONSTRUCCIÓN DEL EGRESO DE LA HACIENDA PROVINCIAL DE YUCATÁN (CAJAS DE MÉRIDA Y CAMPECHE) EN EL PERIODO $1801-1820$

\begin{tabular}{|c|c|c|}
\hline & Caja de Mérida & Caja de Campeche \\
\hline Año & Referencia & Referencia \\
\hline 1801 & TePaske y Klein (1986-1988) & TePaske y Klein (1986-1988) \\
\hline 1802 & TePaske y Klein (1986-1988) & n. d. \\
\hline 1803 & TePaske y Klein (1986-1988) & TePaske y Klein (1986-1988) \\
\hline 1804 & n. d. & n. d. \\
\hline 1805 & n. d. & TePaske y Klein (1986-1988) \\
\hline 1806 & TePaske y Klein (1986-1988) & AGN, CM, vol. 1.159 \\
\hline 1807 & n. d. & TePaske y Klein (1986-1988) \\
\hline 1808 & TePaske y Klein (1986-1988) & n. d. \\
\hline 1809 & AGI, México, leg. 3.145 & AGN, CM, caja 567 \\
\hline 1810 & AGN, IV, caja 6.302 , exp. 1 & AGN, CM, vol. 992 \\
\hline 1811 & AGN, CM, vol. 1.906 & AGN, CM, vol. 2.198 \\
\hline 1812 & AGN, CM, vol. 2.772 & TePaske y Klein (1986-1988) \\
\hline 1813 & AGI, México, leg. 3.145 & n. d. \\
\hline 1814 & AGI, México, leg. 3.145 & n. d. \\
\hline 1815 & AGI, México, leg. 3.145 & TePaske y Klein (1986-1988) \\
\hline 1816 & TePaske y Klein (1986-1988) & AGN, CM, caja 501 \\
\hline 1817 & AGN, AHH, vol. 660, exp. 4 & AGN, AHH, vol. 660 , exp. 3 \\
\hline 1818 & AGN, AHH, vol. 940, exp. 1 & AGN, AHH, vol. 941, exp. 1 \\
\hline 1819 & AGI, México, leg. 3.147 & AGN, AHH, vol. 570, exp. 8 \\
\hline 1820 & n. d. & AGN, IV, caja 5.399, exp. 2 \\
\hline
\end{tabular}




\section{APÉNDICE 1.C}

Situados recibidos por la caja de Campeche de la caja de Veracruz (1801-1820) 1801: TePaske y Klein (1986-1988); 1802: AGN, CM, vol. 684; 1803: CM, vol. 748; 1804: n. d.; 1805: AGN, CM, vol. 654; 1806: n. d.; 1807: AGN, CM, vol. 671; 1808: AGN, CM, vol. 202; 1809: AGN, CM, vol. 854; 1810: n. d.; 1811: AGN, CM, vol.744; 1812: AGN, CM, vol. 682; 1813: AGN, CM, vol. 626; 1814: AGN, CM, vol. 666; 1815: AGN, CM, vol. 605; 1816: AGN, CM, vol. 649; 1817: AGN, CM, vol. 667; 1818: AGN, CM, vol. 631; 1819: n. d.; 1820: AGN, CM, vol. 612 .

\section{FUENTES}

Archivo General de Indias (AGI), Sevilla.

Archivo General Militar de Madrid (AGMM), Madrid.

Archivo General de la Nación (AGN), México D. F.

- Archivo Histórico de Hacienda (AHH), AGN, México D. F.

- Caja Matriz (CM), AGN, México D. F.

- Indiferente virreinal (IV), AGN, México D. F.

- Real Hacienda (RH), AGN, México D. F.

- Infidencias (In), AGN, México D. F. 